(2) Open Access Full Text Article

ORIGINALRESEARCH

\title{
Hyperuricemia Among Egyptian Rheumatoid Arthritis Patients. Is It an Association or an Inflammatory Marker? A Cross-Sectional Observational Study
}

\author{
Doaa Nada (iD ${ }^{\prime}$ \\ Rasha Gaber ${ }^{2}$ \\ Al Shymaa Mahmoud ${ }^{3}$ \\ Radwa Elkhouly (D) \\ Doaa Alashkar \\ 'Rheumatology and Rehabilitation \\ Department, Faculty of Medicine, Tanta \\ University, Tanta, Al Gharbeia \\ Governorate, Egypt; ${ }^{2}$ Medical \\ Biochemistry Department, Faculty of \\ Medicine, Tanta University, Tanta, Al \\ Gharbeia Governorate, Egypt; ${ }^{3}$ Radiology \\ Departments, Faculty of Medicine, Tanta \\ University, Tanta, Al Gharbeia \\ Governorate, Egypt
}

Objective: To detect the prevalence of hyperuricemia in Egyptian rheumatoid arthritis (RA) patients as well as to assess its association with the severity of joint inflammation and disease-modifying antirheumatic drugs (DMARDs) in those patients.

Methods: A total of 150 RA patients were recruited; all patients were subjected to (1) clinical and functional assessment by disease activity score in 28 joints (DAS28) and modified health assessment questionnaire (MHAQ). (2) Laboratory investigations: serum uric acid (SUA) level, complete blood count (CBC), erythrocyte sedimentation rate (ESR), C-reactive protein (CRP), rheumatoid factor (RF), anti-cyclic citrullinated peptide (anti$\mathrm{CCP}$ ), tumor necrosis factor $\alpha(\mathrm{TNF}-\alpha)$, interleukin 1 (IL1), and interleukin 6 (IL6) levels. (3) Radiological evaluation: (A) plain X-ray of both hands and feet; (B) musculoskeletal ultrasound (MSUS) of both wrists, hands, shoulder, ankle, and knee joints.

Results: SUA was significantly correlated with disease activity by DAS28. Acute-phase reactants and inflammatory markers (IL1 $\beta$, IL6, and TNF- $\alpha$ ) were also significantly elevated in RA patients with low and high hyperuricemia compared to those with normal SUA. A total of $90 \%$ of RA patients with low hyperuricemia had synovial proliferation with power Doppler $(1+$ and $2+)$, and 30 patients had mild effusion $(1+)$, while nearly all patients with high hyperuricemia had hypoechoic synovial proliferation $(2+$ and $3+)$, and 20 patients had moderate effusion. However, $70 \%$ RA patients with normal serum uric acid showed mild synovitis and effusion (1+). No significant association was found between the administered DMARDs and levels of SUA as well as inflammatory markers; however, high-dose steroid treatment was associated with high SUA level.

Conclusion: Elevation of serum uric acid levels in Egyptian RA patients was prevalent and might be an inflammatory marker for severity of joint inflammation. Moreover, higher doses of steroids could be considered a cause of hyperuricemia.

Keywords: rheumatoid arthritis, uric acid, inflammatory marker, hyperuricemia

\section{Introduction}

Rheumatoid arthritis (RA) is a chronic autoimmune disease that causes both systemic and articular inflammation, especially of the small joints of the hands and feet. Gout, on the other hand, is an inflammatory arthropathy caused by the deposition of articular and peri-articular monosodium urate monohydrate (MSU) crystals occurring in the framework of chronic hyperuricemia. ${ }^{1}$ The coexistence of hyperuricemia and RA has been thought to be extremely rare, ${ }^{1}$ although many
Correspondence: Doaa Nada Rheumatology and Rehabilitation Department, Faculty of Medicine, Tanta

University, Geish Street, Tanta, Al

Gharbeia Governorate, Egypt

Tel +201069579672

$\mathrm{Fax}+23286114040$

Email doaa.waseem@yahoo.com 
studies showed that its prevalence may reach more than $5 \%$ in patients with $\mathrm{RA}^{2}{ }^{2}$ challenging the previous concepts that hyperuricemia and RA are mutually exclusive conditions. ${ }^{3}$ The identification of hyperuricemia in RA patients may have additional implications apart from the potential misclassification of either condition. ${ }^{3}$ Hyperuricemia has been associated with an approximately 2 -fold increased risk of cardiovascular disease and mortality in comparison to the general population, suggesting that serum urate concentrations might be of prognostic value in RA patients. ${ }^{4-7}$ Moreover, serum uric acid (UA) concentrations are strongly correlated with renal dysfunction in RA patients, highlighting the benefit of serum UA as a biomarker for early detection of renal impairment. ${ }^{8-11}$ All these studies suggest that both hyperuricemia and gout are more common in RA patients than previously known and may predict important long-term consequences. However, the potential effect of hyperuricemia and/or gout on RA disease activity, medication selection, and long-term outcomes remains unknown. Hence, the aim of our study is to detect the prevalence of hyperuricemia in Egyptian RA patients as well as to assess its association with the severity of joint inflammation and diseasemodifying anti-rheumatic drugs (DMARDs) in those patients.

\section{Materials and Methods}

We confirm that none of the present study's procedures violated the principles stated by the latest version of the Declaration of Helsinki. ${ }^{12}$ We followed the recommendations of STROBE guidelines during the preparation of this manuscript. ${ }^{13}$

\section{Study Design and Patients}

This is a cross-sectional observational study that was carried out on 175 RA patients in the Physical Medicine, Rheumatology \& Rehabilitation Department, Tanta University Hospital in the period between September 2019 and March 2020. In this study, we selected 150 RA patients receiving different types of DMARD therapy. Those patients fulfilled the American College of Rheumatology (ACR)/ European League Against Rheumatism (EULAR) 2010 criteria for diagnosis of rheumatoid. ${ }^{14}$

\section{Exclusion Criteria}

Twenty-five RA patients with malignancy or under chemotherapy, with cardiovascular diseases, metabolic syndrome, and infectious diseases, and pregnant females were excluded from this study. However, patients on urate-lowering medications with persistent hyperuricemia were included. All investigations were explained to all patients before having their written informed consents to participate in this study.

\section{Methods}

All patients were subjected to the following:

1. Full history taking, general examination, and local rheumatologic examination (joint pain, tenderness, swelling, and limitation of joint motion).

2. Assessment of disease activity, using DAS28 score. $^{15}$

3. Functional assessment, using modified health assessment questionnaire (MHAQ). ${ }^{16}$

4. Laboratory evaluation:

A) Serum uric acid level was determined using enzymatic-colorimetric methods (Roche Diagnostics, $\mathrm{GmbH}$, Mannheim, Germany). Hyperuricemia was defined as a serum urate concentration $>7.5 \mathrm{mg} / \mathrm{dL}$ in men and $>6.2 \mathrm{mg} / \mathrm{dL}$ in women. ${ }^{17}$

B) Complete blood count (CBC). ${ }^{18}$

C) Erythrocyte sedimentation rate (ESR). ${ }^{19}$

D) C-reactive protein (CRP). ${ }^{19}$

E) Rheumatoid factor (RF) was assayed by the 2-minute hemagglutination slide test (Wampole Laboratories, $\mathrm{NJ}$ ). A test at 1:10 dilution was considered positive. ${ }^{20}$

F) Anti-cyclic citrullinated peptide (anti-CCP). ${ }^{20}$

G) Inflammatory cytokines including serum levels of interleukin 1 (IL1), interleukin 6 (IL6), and tumor necrosis factor $\alpha$ (TNF- $\alpha$ ) were measured by enzyme-linked immunosorbent assay (ELISA) using ultrasensitive commercial kits (Human Ultrasensitive, BioSource International Inc., Camarillo, CA, USA). ${ }^{21}$

5. Radiological evaluation:

A) Plain X-ray of both hands and feet, to detect any bone erosion. ${ }^{22}$

B) Musculoskeletal ultrasonography (MSUS) of both wrists, metacarpophalangeal (MCP), interphalangeal (IP), shoulders, ankle, and knee joints was performed using $15 \mathrm{MHz}$ high-resolution linear array transducers with small footprints; scans of the joints were performed in the dorsal and palmar/plantar planes. ${ }^{23}$

\section{Statistical Methods}

Statistical analysis was done using SPSS 20 software and results expressed as mean $\pm \mathrm{SD}$. Comparison of variables 
between two groups was performed with Student's $t$-test for continuous variables. The $p$-values $<0.05$ were considered statistically significant. ${ }^{24}$

\section{Results}

One hundred and fifty RA patients who met the inclusion criteria were studied. They included 25 males and 125 females, with a mean age of $43.8 \pm 14.7$ years. Most of our patients have BMI of $>25$ to $\leq 30(90 \%)$, and $(10 \%)$ have BMI of $>30$ to $\leq 35$. Sixty percent of them have hyperuricemia (Table 1). Significantly higher SAU levels were detected among males and post-menopausal women in our study $(p<0.01$ and $p<0.001$, respectively). Moreover, a statistically significant positive correlation was noticed between SUA levels and age $(p=0.003)$, gender $(p=0.004)$, high body mass index (BMI) $(p=0.014)$, and high doses of steroids $(p=0.001)$. The clinical and laboratory findings of RA patients in the study group are summarized in Table 2. Fifty-five RA patients with low hyperuricemia had moderate disease activity (3.147 \pm 1.813 ) by DAS28, while 35 patients with high hyperuricemia had severe disease activity by DAS28 (5.177 \pm 1.823 ); however, 60 RA patients with normal serum uric acid showed low disease activity (2.157 \pm 1.811$)$. The acute-phase reactants as well as inflammatory cytokines (IL1 $\beta$, IL6, and TNF- $\alpha$ ) were also significantly elevated in RA patients with low and high hyperuricemia compared to those with normal serum uric acid (Table 2). Regarding the musculoskeletal ultrasonography, $90 \%$ of RA patients with low hyperuricemia had hypoechoic synovial proliferation with increased blood flow by power Doppler $(1+$ and $2+)$, and 30 patients had mild effusion $(1+)$, while nearly all patients with high hyperuricemia had hypoechoic synovial proliferation with increased blood flow by power Doppler (2+ and 3+), and 20 patients had moderate effusion. However, 70\% RA patients with normal serum uric acid

Table I Demographic and Clinical Data of RA Patients

\begin{tabular}{|c|c|c|c|c|}
\hline \multirow[t]{2}{*}{ Demographic and Clinical Data } & $\begin{array}{c}\text { RA with Low } \\
\text { Hyperuricemia }(6.2 \\
-8 \mathrm{mg} / \mathrm{dL})(n=55)\end{array}$ & $\begin{array}{l}\text { RA with High } \\
\text { Hyperuricemia (8.2- } \\
\text { I I.6 mg/dL) }(n=35)\end{array}$ & $\begin{array}{c}\text { RA with Normal SUA } \\
\begin{array}{c}(4.8-6.0 \mathrm{mg} / \mathrm{dL}) \\
(n=60)\end{array}\end{array}$ & \multirow[t]{2}{*}{$P$-value } \\
\hline & Mean $\pm S D$ & Mean \pm SD & Mean \pm SD & \\
\hline Age (years) & $45.4 \pm 14.3$ & $43.8 \pm 14.7$ & $46.222 \pm 10.92$ & $0.01^{*}$ \\
\hline Disease duration (years) & $7.3 \pm 11.6$ & $8.1 \pm 9.5$ & $10.378 \pm 6.590$ & $0.01 *$ \\
\hline Duration of morning stiffness (minutes) & $82.7 \pm 50.2$ & $87.4 \pm 58.9$ & $80.89 \pm 30.31$ & $0.001 * *$ \\
\hline Number of swollen joints & $7.667 \pm 6.51$ & $9.667 \pm 8.51$ & $6.667 \pm 4.51$ & $0.001 * *$ \\
\hline Number of tender joints & $7.556 \pm 8.109$ & $10.556 \pm 9.109$ & $5.556 \pm 7.109$ & $0.001 * *$ \\
\hline DAS28 & $3.147 \pm 1.813$ & $5.177 \pm 1.823$ & $2.157 \pm 1.81 \mid$ & $0.001 * *$ \\
\hline MHAQ & $0.508 \pm 0.410$ & $0.608 \pm 0.407$ & $0.408 \pm 0.207$ & $0.001 * *$ \\
\hline
\end{tabular}

Notes: Except where indicated otherwise, values are expressed as mean \pm standard deviation. *Significant $p$-value $\leq 0.05$, ** $p$-value $\leq 0.00$ I.

Abbreviations: DAS28, disease activity score in 28 joints; $n$, number; RA, rheumatoid arthritis; MHAQ, modified health assessment questionnaire.

Table 2 Laboratory Findings in RA Patients

\begin{tabular}{|c|c|c|c|c|}
\hline \multirow[t]{2}{*}{$\begin{array}{l}\text { Biochemical } \\
\text { Parameters }\end{array}$} & $\begin{array}{l}\text { RA with Low Hyperuricemia } \\
\qquad(n=55)\end{array}$ & $\begin{array}{l}\text { RA with High Hyperuricemia } \\
\qquad(n=35)\end{array}$ & $\begin{array}{l}\text { RA with Normal SUA } \\
\qquad(n=60)\end{array}$ & \multirow[t]{2}{*}{$P$-value } \\
\hline & Mean士SD & Mean士SD & Mean士SD & \\
\hline ESR $I^{\text {st }} \mathrm{h}(\mathrm{mm} / \mathrm{h})$ & $40.034 \pm 19.77$ & $40.044 \pm 23.97$ & $|4.4 \pm 6.7|$ & $<0.001 * *$ \\
\hline CRP (mg/dL) & $10.6 \pm 4.109$ & $11.6 \pm 7.169$ & $4.8 \pm|.75|$ & $<0.00 I^{* *}$ \\
\hline RF titer & $49.52 \pm 17.87$ & $51.52 \pm 19.89$ & $42.50 \pm 10.58$ & $<0.00 I^{* *}$ \\
\hline Anti-CCP titer & $40 \pm 14.90$ & $48 \pm 13.40$ & $38.30 \pm 9.95$ & $<0.00 I^{* *}$ \\
\hline ILI $\beta$ (pg/mL) & $14.33 \pm 5.67$ & $16.05 \pm 7.67$ & $10.56 \pm 6.38$ & $<0.001^{* *}$ \\
\hline IL6 (pg/mL) & $|8.44 \pm 6.8|$ & $20.81 \pm 11.16$ & $|4.5 \pm 9.3|$ & $<0.00 I^{* *}$ \\
\hline TNF- $\alpha(\mathrm{pg} / \mathrm{mL})$ & $40.34 \pm|3.7|$ & $46.54 \pm 13.76$ & $36.24 \pm 13.75$ & $<0.00 I^{* *}$ \\
\hline
\end{tabular}

Notes: Values are expressed as mean \pm standard deviation. **Significant $p$-value $\leq 0.001$.

Abbreviations: CRP, C-reactive protein level; ESR, erythrocyte sedimentation rate; $n$, number; RF, rheumatoid factor; Anti-CCP, anti-cyclic citrullinated peptide; ILI $\beta$, interleukin I $\beta$; IL6, interleukin 6; TNF- $\alpha$, tumor necrosis factor $\alpha$. 
Table 3 Radiographic Features of RA Patients (The Presence/Absence of Synovitis and/or Erosions) by Musculoskeletal Ultrasound as Well as Plain X-Ray Findings

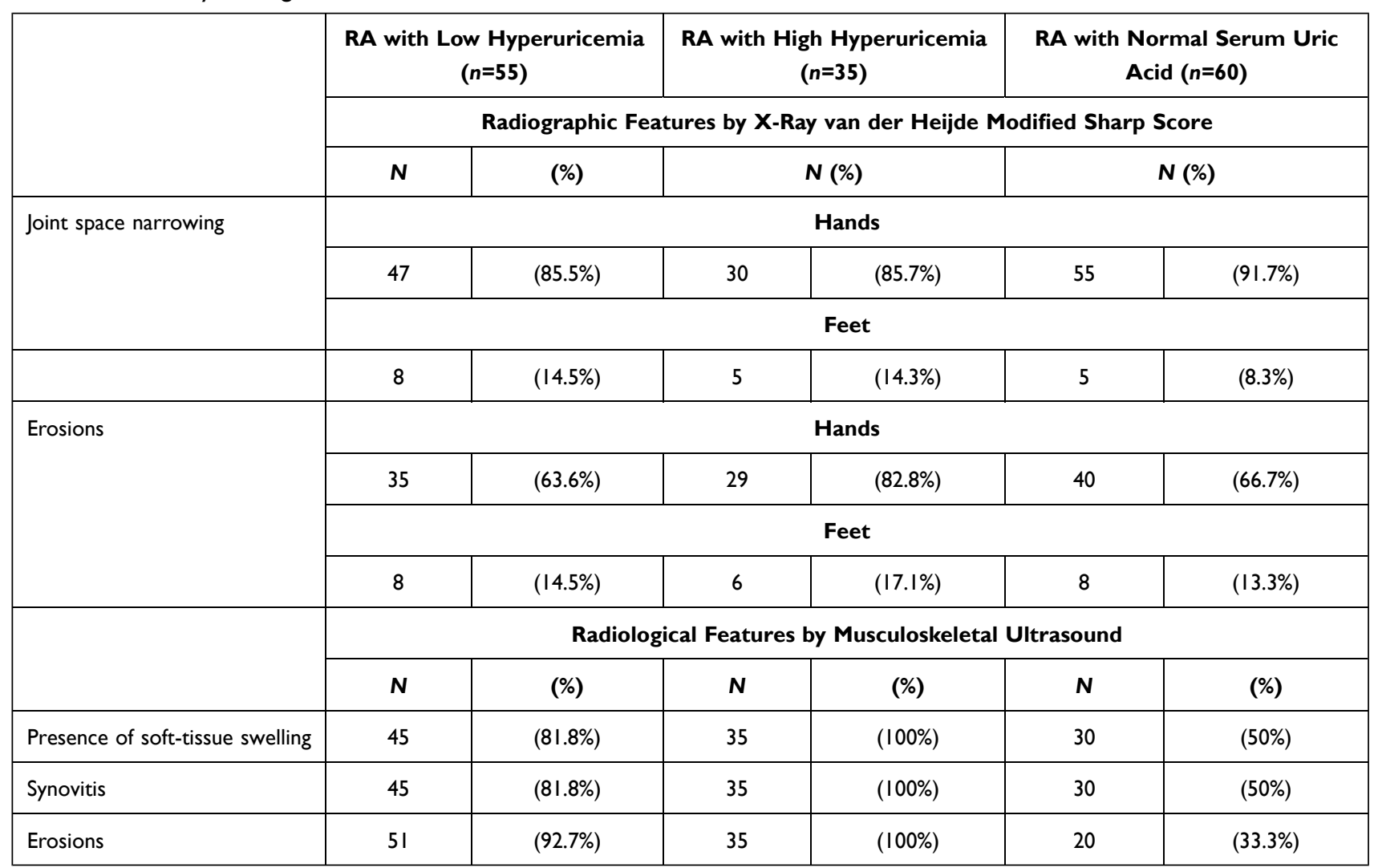

showed mild synovitis and effusion (1+) (Table 3 and Figures 1-3). As regards the serum level of different inflammatory markers and its relation to serum uric acid level, its linear regression relationship in RA patients is demonstrated in Table 4. Most of RA patients received combined therapy (MTX+leflunomide $[n=36,24 \%]$ or MTX+hydroxychloroquine $[n=99,66 \%])$ besides NSAIDs and corticosteroids. Methotrexate was the most common DMARD monotherapy used by the remaining 15 $(10 \%)$ of the studied RA patients. We did not find a significant association between the administered DMARDs, inflammatory biomarkers, and levels of serum $\mathrm{UA}(p=0.063, p=0.764)$ in RA patients who received MTX +leflunomide $(p=0.84, p=0.431)$, or in patients who received MTX+hydroxychloroquine $(p=0.097, p=0.137)$, or in patients who received MTX as monotherapy, respectively. Moreover we found that high-dose steroid treatment was associated with increased SUA levels $(p=0.052)$.

\section{Discussion}

It was assumed that the prevalence of hyperuricemia in RA patients was significantly lower than the expected age- and sex-specific prevalence rate from the general population. ${ }^{25}$ This is attributed to the possibility that estrogens and progesterone cause better renal clearance of uric acid in women with RA, decreasing the risk of hyperuricemia in these patients. ${ }^{26}$ Glucocorticoids and NSAIDs used in treatment of RA can also potentially mask the clinical manifestations of hyperuricemia, in addition to IL6 that may reduce the likelihood of hyperuricemia and gout owing to its uricosuric properties. ${ }^{27} \mathrm{~A}$ total of $75 \%$ of RA patients involved in this study were on glucocorticoid therapy and $81 \%$ on NSAIDs at some point during their follow-up. So, we can consider that potential cases of hyperuricemia and gout never clinically developed. Also, we did not perform polarized microscopy for synovial fluid of most RA patients enrolled in this study. For these reasons it is possible that some of our RA patients who developed gout may have been missed in our study.

Moreover, hyperuricemia and gout occurred more frequently in RA patients diagnosed in recent years than among patients with RA diagnosed in earlier years. The reasons for this increased incidence in RA patients in the recent years is unclear; however, this may be due to an 


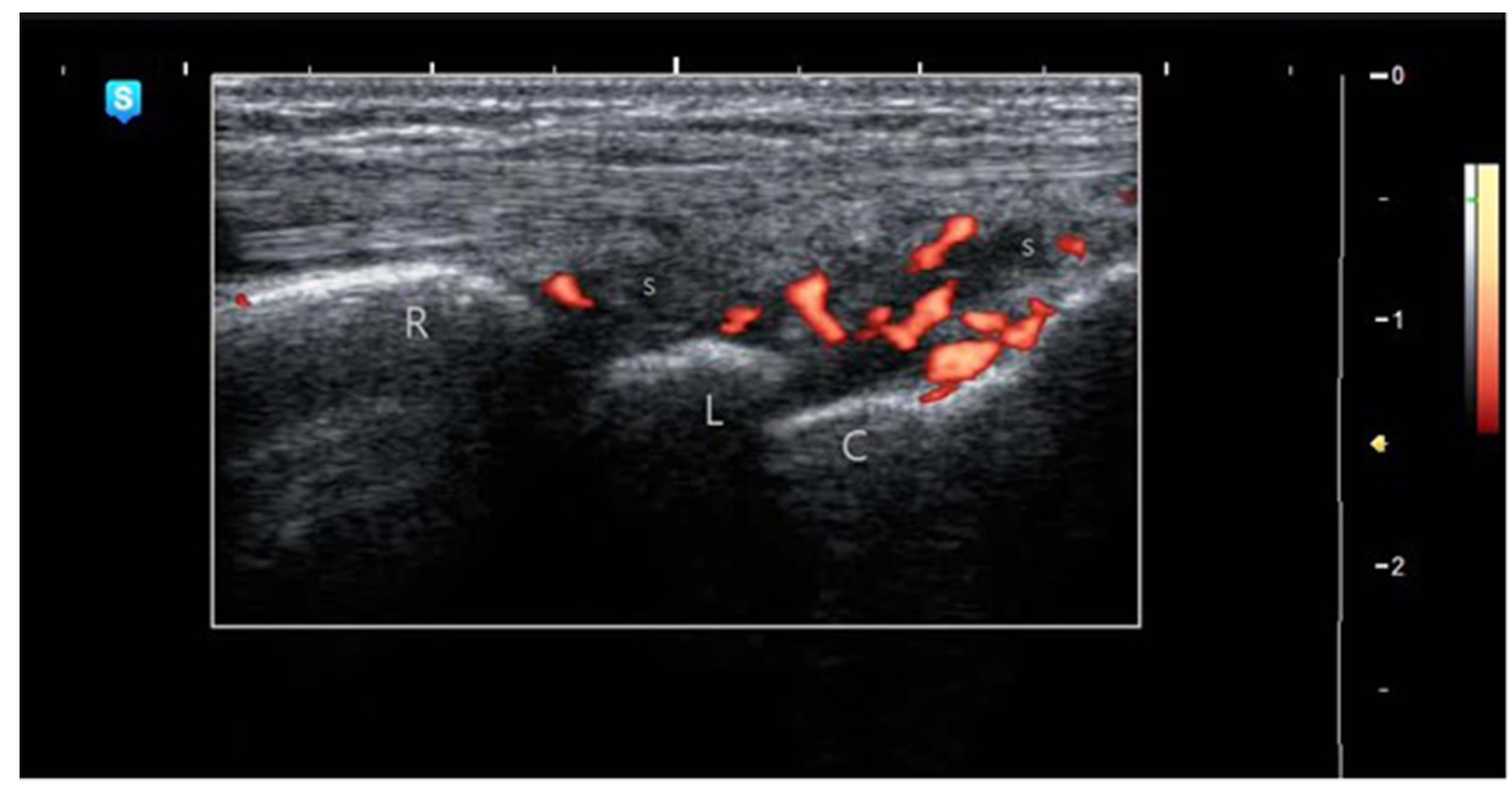

Figure I Long-axis view with power Doppler ultrasound of left wrist joint in 54-year-old female RA patient with high hyperuricemia (uric acid=8.4 mg/dL) showing synovitis grade 3 in radiocarpal joint.

Abbreviations: $\mathrm{R}$, radius bone; L, lunate bone; C, capitate bone; S, synovitis.

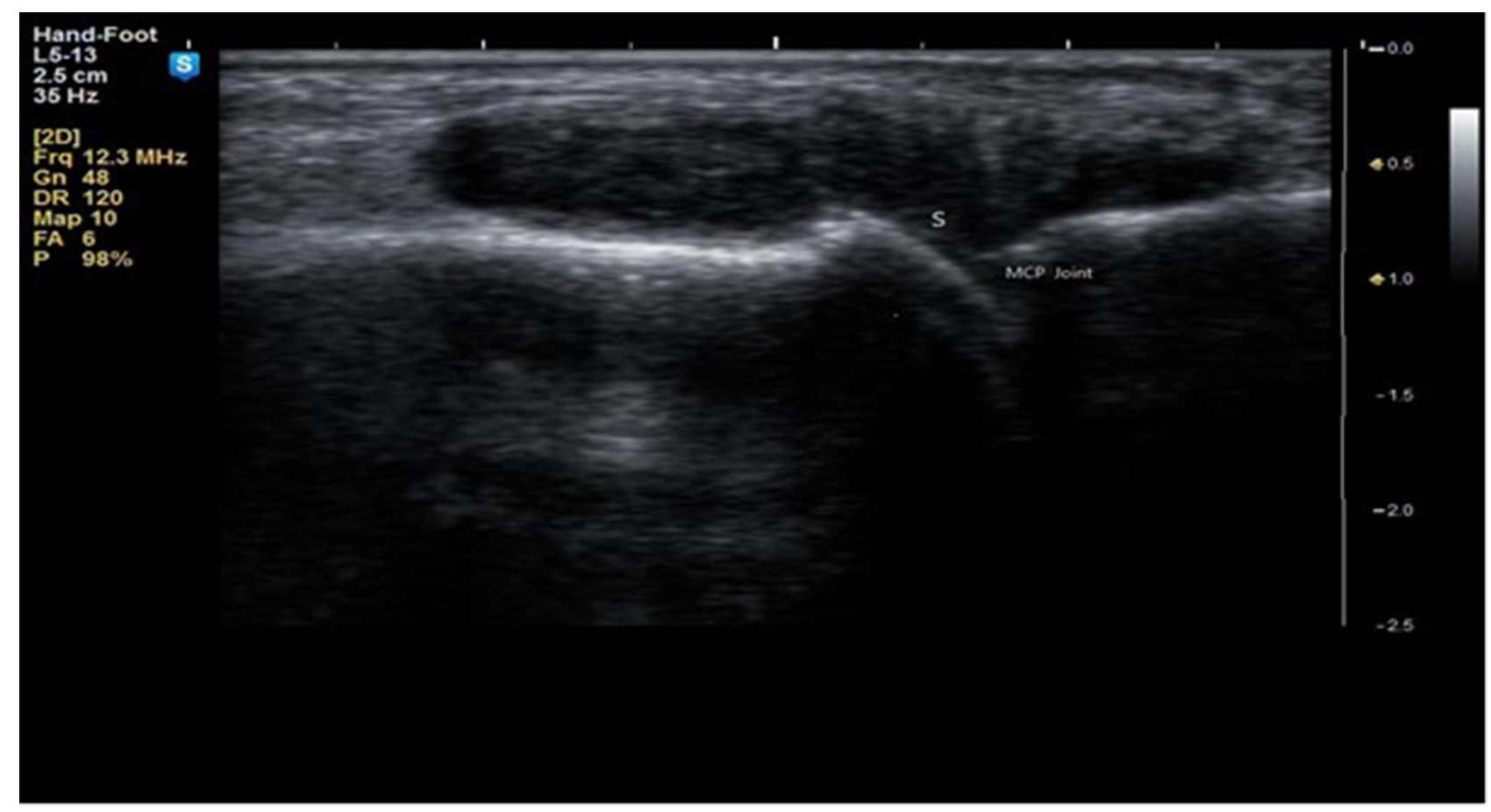

Figure 2 Gray-scale US long-axis view of MCP joint of right index finger of the same patient showing synovitis grade 3 (synovial hypertrophy and effusion). Abbreviations: MCP, metacarpophalangeal joint; S, synovitis.

increase in the incidence of risk factors for hyperuricemia, such as hypertension, obesity, and chronic kidney disease in the recent years. The use of aspirin which has uricosuric properties in patients with RA in the earlier decades may also explain the lower incidence of gout in these patients. ${ }^{28}$ In our study, age and male sex were noticed to be risk factors for hyperuricemia in RA patients, and are considered also as risk factors for hyperuricemia identified 


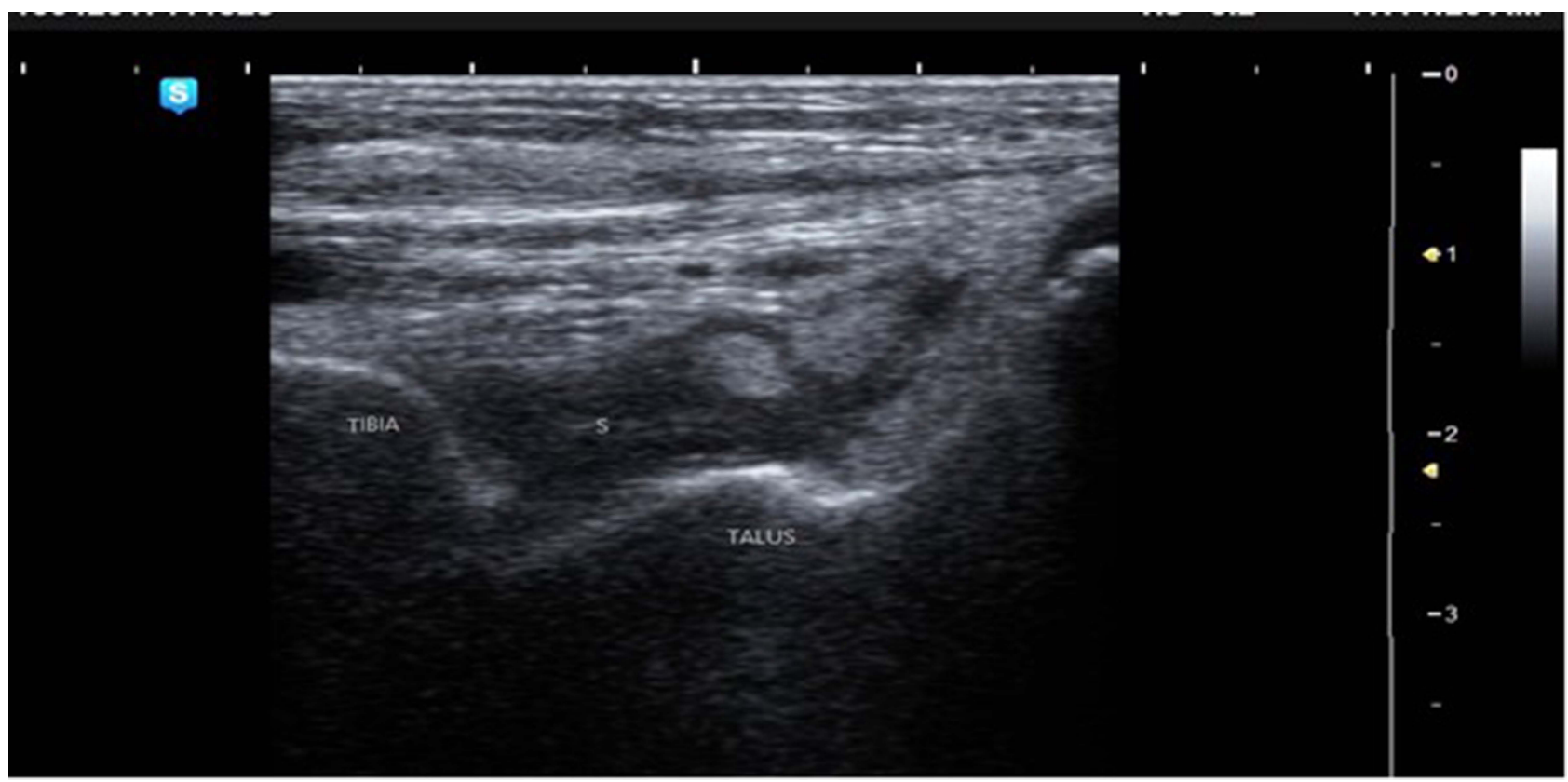

Figure 3 Long-axis view gray-scale US of right ankle joint in the same patient showing tibiotalar joint synovitis grade 3 (synovial hypertrophy and effusion). Abbreviation: S, synovitis.

in the general population. ${ }^{28}$ Obesity, on the other hand, is not considered as a risk factor in this study as most of our patients have BMI of $>20$ to $\leq 25$ (90\%), and (10\%) have BMI of $>25$ to $\leq 30$. Sixty percent of them have hyperuricemia.

As regards the acute-phase reactants (ESR and CRP) as well as inflammatory markers (IL1 $\beta$, IL6, and TNF- $\alpha$ ), these were also significantly elevated in the studied RA patients with low and high hyperuricemia compared to those with normal serum uric acid. This is in agreement with Rosangela et al, who found significant correlation between serum C-reactive protein and UA levels, ${ }^{29}$ and with Anker et al, who also found a significant positive correlation between serum UA and elevation of inflammatory markers in heart failure patients. ${ }^{30}$ Moreover, other studies have demonstrated that after cellular death or injury, the degradation of nucleotides into UA serves as an endogenous trigger for the maturation as well as immune-stimulatory action of dendritic cells. ${ }^{31}$

Also, a positive and significant association between serum UA and inflammatory markers such as interleukin $1 \beta$ (IL1 $\beta$ ), interleukin 6 (IL6), and tumor necrosis factor $\alpha$ $(\mathrm{TNF}-\alpha)$ synthesis was reported in many experimental studies. ${ }^{32}$ Moreover, it stimulates the release of chemokine chemo-attractant protein $1{ }^{33}$ These findings suggest the linear relationship between serum UA and inflammatory

Table 4 The Linear Regression Relationship of Inflammatory Markers (Log-Transformed Values) with Different Uric Acid Levels in RA Patients

\begin{tabular}{|c|c|c|c|c|}
\hline \multirow[t]{2}{*}{ Biomarkers } & \multicolumn{4}{|c|}{ Serum Uric Acid } \\
\hline & $4.8-6.0 \mathrm{mg} / \mathrm{dL}(n=60)$ & $6.2-8 \mathrm{mg} / \mathrm{dL}(n=55)$ & $8.2-11.6 \mathrm{mg} / \mathrm{dL}(n=35)$ & $P$-value \\
\hline CRP (mg/mL) & $2.6 \pm 0.60$ & $3.0 \pm|.5|$ & $3.5 \pm 0.51$ & $<0.001 * *$ \\
\hline $\operatorname{ESR}(\mathrm{mm} / \mathrm{h})$ & $13.6 \pm 2.2$ & $16.8 \pm 3.21$ & $16.0 \pm 2.23$ & $<0.001 * *$ \\
\hline $\operatorname{ILI} \beta(\mathrm{pg} / \mathrm{mL})$ & $1.0 \pm 0.50$ & $1.6 \pm 0.24$ & $2.0 \pm 0.53$ & $0.001 * *$ \\
\hline IL6 (pg/mL) & $1.4 \pm 0.32$ & $1.5 \pm 0.92$ & $2.7 \pm 0.34$ & $<0.00 I^{* *}$ \\
\hline TNF- $\alpha(\mathrm{pg} / \mathrm{mL})$ & $11.3 \pm 1.00$ & $12.4 \pm 0.89$ & $13.8 \pm 0.78$ & $<0.01 *$ \\
\hline
\end{tabular}

Notes: Data are expressed as mean \pm SE. Categorical variables were compared by $\mathrm{X}^{2}$ test. Comparisons between 3 groups were performed using a general linear model. $P$-values refer to results after analysis with adjustment for age, sex, and body mass index. ** $p$-value $\leq 0.00$ I, *significant $p$-value $\leq 0.05$.

Abbreviations: CRP, C-reactive protein; ESR, erythrocyte sedimentation rate; $n$, number; ILI $\beta$, interleukin I $\beta$; IL6, interleukin 6 ; TNF- $\alpha$, tumor necrosis factor $\alpha$ were logtransformed for statistical analysis. 
markers, and such a relationship may be clinically relevant even in subjects with normal serum UA as in our study. However, the details of such a relationship remains unknown.

Our results did not confirm whether UA is a proinflammatory marker or a cause of joint inflammation in RA patients, but considerable pre-clinical data support the latter hypothesis. The soluble UA activates the proliferation of vascular smooth muscle cells, up-regulates the cyclo-oxygenase- 2 activity and vascular C-reactive protein, as well as stimulates the pro-inflammatory response. $^{34,35}$ Also, human mononuclear cells that are exposed to UA may increase their production of IL1 $\beta$, IL6, and TNF- $\alpha$, whereas neutrophils release proinflammatory proteins. ${ }^{32}$

Hence, all these findings support the idea that elevated serum UA may negatively affect the joints, perhaps by activating a more complex vicious cycle involving inflammatory and oxidative related mechanisms. Briefly, in RA patients, the chronic hypoxia causes cellular damage that up-regulates the xanthine oxidase enzyme, leading to parallel increase of UA and free radical production, resulting in endothelial dysfunction. ${ }^{36}$ Pro-inflammatory cytokines (TNF- $\alpha$, IL1, and IFN- $\gamma$ ) may increase UA production through the enhancement of xanthine oxidase enzyme activity, as well as the promotion of apoptosis. ${ }^{37,38}$ Hence, UA released from cytoplasm into local tissue micro-environments may increase the inflammatory immune responses, even when its concentration is within normal physiological limits, ${ }^{39}$ and this may explain the severity of synovitis in our RA patients whether with normal serum UA or with high or low hyperuricemia.

Likewise, Andrew et al found that there was no association of hyperuricemia or gout with measures of RA disease activity or severity and attributed that to the use of disease-modifying anti-rheumatic drugs and/or other potent anti-inflammatory treatments in RA patients. ${ }^{40}$

Moreover, Carlos et al showed in their case study that the prevalence of persistent hyperuricemia may have an anti-inflammatory or immunosuppressive role in rheumatoid arthritis and may protect against or decrease the joint inflammation via blocking the sensitization to antigens which may cause RA and may also block the production of immunocompetent lymphocytes. ${ }^{41}$ The mutual exclusivity of gout and rheumatoid arthritis may relate to the immunosuppressive effect of urate crystals. ${ }^{42}$ Ames et al have shown that uric acid is a powerful antioxidant and scavenger of singlet oxygen and other active free radicals. They have proposed that it acts as a protective mechanism in humans, lengthening life span and decreasing rates of age-specific cancer and perhaps other diseases. $^{43}$

Ninety percent of our RA patients with low hyperuricemia had hypoechoic synovial proliferation with increased blood flow by power Doppler $(1+$ and $2+)$, and 30 patients had mild effusion $(1+)$, while nearly all patients with high hyperuricemia had hypoechoic synovial proliferation with increased blood flow by power Doppler (2+ and 3+), and 20 patients had moderate effusion. However, 70\% RA patients with normal serum uric acid showed mild synovitis and effusion $(1+)$. Power Doppler ultrasonography (PDUS) was able to detect subclinical synovitis in $50 \%$ of studied RA patients with low disease activity or even in clinical remission with normal SUA; this is in agreement with other studies that showed superiority of ultrasonography in detecting subclinical activity through the presence of positive power Doppler signals in RA patients. ${ }^{44,45}$

Our findings raised an important question, whether hyperuricemia plays any role in directly increasing joint inflammation or whether it is just a pro-inflammatory marker for an adverse metabolic profile that promotes progression of synovitis. We think that observational studies such as ours cannot definitively distinguish between these two possibilities, but it is potentially useful to speculate whether hyperuricemia is a cause or a marker. It has been proposed recently that hyperuricemia, rather than being simply a marker, might contribute to oxidative stress, systemic as well as joint inflammation. ${ }^{46}$ Hyperuricemia can also induce endothelial dysfunction and reduced bioavailability of endothelial nitric oxide and can cause and promote the progression of chronic synovitis, ${ }^{47}$ whereas treatment with allopurinol can improve endothelial function in patients with hyperuricemia. $^{48}$

Most of RA patients received combined therapy (MTX +leflunomide $[n=36,24 \%]$ or MTX+hydroxychloroquine $[n=99,66 \%])$ besides NSAIDs and corticosteroids. Methotrexate was the most common DMARD monotherapy used by the remaining $15(10 \%)$ of the studied RA patients. We did not find significant association between the administered DMARDs as well as inflammatory biomarkers and levels of serum UA ( $p=0.063, p=0.764$ ) in RA patients who received MTX+leflunomide $(p=0.84, p=0.431$ ) in patients who received MTX+hydroxychloroquine $(p=0.097$, $p=0.137$ ), and in patients who received MTX as monotherapy, respectively. Moreover we found that high-dose steroid 
treatment was associated with increased SUA level $(p=0.052)$. Other studies have proposed that glucocorticoids and NSAIDs commonly used in RA patients could mask the inflammatory manifestations of hyperuricemia, ${ }^{2}$ which was offered as an explanation for earlier conclusions that gout was rarely diagnosed in the context of established RA. ${ }^{49}$

Andrew et al compared RA patients with gout and gout-free participants who were taking NSAIDs at enrollment. They found that avoidance of these medications in RA patients with gout may relate to a higher prevalence of joint inflammation. Also, the use of NSAIDs could have masked the clinical symptoms of gout in a limited number of hyperuricemic RA patients, and it has also been proposed that various pro-inflammatory cytokines in RA might exert uricosuric effects and therefore reduce the likelihood of patients to develop gouty arthritis. ${ }^{40}$ Counter to our study hypothesis, we found no differences in the use of therapies that might affect cytokine concentrations (eg, methotrexate, prednisone, or leflunomide therapies) whether based on serum UA concentration or gout status at the time of enrollment into this RA registry.

\section{Limitations of This Study}

First, because of the cross-sectional nature of this study, a casual pathway from UA to inflammation is suggested but not definitively proven by our findings. In addition, we could only measure the circulating UA, which is only a weak reflection of tissue deposits. Despite these limitations, our findings may have significant clinical value. The increased level of inflammatory markers as well as the progressively higher percentage of subjects with abnormally elevated inflammatory markers alongside the UA levels suggests that UA might contribute to the proinflammatory condition that characterizes RA.

\section{Conclusion}

Elevation of serum uric acid levels in RA patients is more frequent and might be an inflammatory marker for severity of joint inflammation. Moreover, there is growing evidence that higher doses of steroids may cause hyperuricemia. Thus, appropriate preventive measures in these patients should be introduced.

\section{Data Sharing Statement}

All data relevant to the study are included in the article.

\section{Ethics Approval}

The protocol of the present study was registered by the local ethics committee of Tanta University Hospital with approval code 21371/9/19.

\section{Author Contributions}

All authors made substantial contributions to conception and design, acquisition of data, or analysis and interpretation of data; took part in drafting the article and revising it critically for important intellectual content; agreed to submit to the current journal; gave final approval of the version to be published; and agree to be accountable for all aspects of the work.

\section{Funding}

No specific funding was received from any bodies in the public, or commercial sectors to carry out the work described in this article.

\section{Disclosure}

The authors declare that the research was conducted in the absence of any commercial or financial relationships that could be construed as a potential conflict of interest.

\section{References}

1. McInnes IB, Schett G. The pathogenesis of rheumatoid arthritis. $N$ Engl J Med. 2011;365(23):2205-2219. doi:10.1056/NEJMra100 4965

2. Jebakumar AJ, Udayakumar PD, Crowson CS, Matteson EL. Occurrence of gout in rheumatoid arthritis: it does happen! A population-based study. Int J Clin Rheumatol. 2013;8:433-437.

3. Petsch C, Araujo EG, Englbrecht M, et al. Prevalence of monosodium urate deposits in a population of rheumatoid arthritis patients with hyperuricemia. Semin Arthritis Rheum. 2016;45:663-668.

4. Cleophas MC, Crisan TO, Joosten LA. Factors modulating the inflammatory response in acute gouty arthritis. Curr Opin Rheumatol. 2017;29:163-170.

5. Schett G, Schauer C, Hoffmann M, Herrmann M. Why does the gout attack stop? A roadmap for the immune pathogenesis of gout. RMD Open. 2015;1(Suppl 1):e000046.

6. Terkeltaub R. What makes gouty inflammation so variable? $B M C$ Med. 2017;15:158.

7. Choi HK, Curhan G. Independent impact of gout on mortality and risk for coronary heart disease. Circulation. 2007;116:894-900.

8. Meek IL, Vonkeman HE, van de Laar MA. Hyperuricaemia: a marker of increased cardiovascular risk in rheumatic patients: analysis of the ACT-CVD cohort. BMC Musculoskelet Disord. 2014;15:174.

9. Kang DH, Nakagawa T, Feng L, et al. A role for uric acid in the progression of renal disease. J Am Soc Nephrol. 2002;13:2888-2897.

10. Daoussis D, Panoulas V, Toms T, et al. Uric acid is a strong independent predictor of renal dysfunction in patients with rheumatoid arthritis. Arthritis Res Ther. 2009;11:R116.

11. Kuo D, Crowson CS, Gabriel SE, Matteson EL. Hyperuricemia and incident cardiovascular disease and non-cardiac vascular events in patients with rheumatoid arthritis. Int $J$ Rheumatol. 2014;20 14:523897. 
12. JAVA. Declaration of Helsinki World Medical Association Declaration of Helsinki. Bull World Health Organ. 2013;79:373-374.

13. Von Elm E, Altman DG, Egger M, et al. The Strengthening the Reporting of Observational Studies in Epidemiology (STROBE) statement: guidelines for reporting observational studies. Int J Surg. 2014;12:1495-1499.

14. Aletaha D, Neogi T, Silman AJ, et al. The 2010 rheumatoid arthritis classification criteria: an American College of Rheumatology/ European League against rheumatism collaborative initiative. Ann Rheum Dis. 2010;62(9):2569-2581.

15. Prevoo ML, Van 'T Hof MA, Kuper HH, et al. Modified disease activity scores that include twenty-eight joint counts. Development and validation in a prospective longitudinal study of patients with rheumatoid arthritis. Arthritis Rheum. 1995;38(1):44-48.

16. Maska L, Anderson J, Michaud K. Measures of functional status and quality of life in rheumatoid arthritis. Arthritis Care Res. 2011;63(11): S4-13.

17. Ruggiero $\mathrm{C}$, Cherubini A, Ble A, et al. Uric acid and inflammatory markers. Eur Heart J. 2006;27(10):1174-1181.

18. Masson C. Rheumatoid anemia. Joint Bone Spine. 2011;78(2):131-137.

19. Yildirim K, Karatay S, Melikoglu MA, et al. Associations between acute phase reactant levels and disease activity score (DAS28) in patients with rheumatoid arthritis. Ann Clin Lab Sci. 2004;34(4):423-426.

20. De Rycke L, Peene I, Hoffman IE, et al. Rheumatoid factor and anticitrullinated protein antibodies in rheumatoid arthritis: diagnostic value, associations with radiological progression rate, and extra-articular manifestations. Ann Rheum Dis. 2004;63(12):1587-1593.

21. Wei S-T, Sun Y-H, Zong S-H, Xiang Y-B. Serum levels of IL-6 and TNF- $\alpha$ may correlate with activity and severity of rheumatoid arthritis. Med Sci Monit. 2015;21:4030-4038.

22. Ory PA. Radiography in the assessment of musculoskeletal conditions. Best Pract Res Clin Rheumatol. 2003;17(3):495-512.

23. Wang Q, Huang QH, Yeow JTW, Pickering MR, Saarakkala S. Quantitative analysis of musculoskeletal ultrasound: techniques and clinical applications. Biomed Res Int. 2017;1:1-2.

24. Dawson-Saunders B, Trapp R. Basic and Clinical Biostatistics. 2nd ed. Lange Medical Book, Prentice- Hall International Inc; 1994.

25. Zhu Y, Pandya BJ, Choi HK. Prevalence of gout and hyperuricemia in the US general population: the National Health and Nutrition Examination Survey 2007-2008. Arthritis Rheum. 2011;63(10):3136-3141.

26. Adamopoulos D, Vlassopoulos C, Seitanides B, Contoyiannis P, Vassilopoulos P. The relationship of sex steroids to uric acid levels in plasma and urine. Acta Endocrinol (Copenh). 1977;85(1):198-208.

27. Choe JY, Lee GH, Kim SK. Radiographic bone damage in chronic Gout is negatively associated with the inflammatory cytokines soluble interleukin 6 receptor and osteoprotegerin. J Rheumatol. 2011;38(3):485-491.

28. Zhu Y, Pandya BJ, Choi HK. Comorbidities of Gout and hyperuricemia in the US general population: NHANES 2007-2008. Am $J$ Med. 2012;125(7):679-687.

29. Rosangela S, Maria AM, Elettra M, et al. Uric acid is associated with inflammatory biomarkers and induces inflammation via activating the NF-кB signaling pathway in HepG2 cells. Arterioscler Thromb Vasc Biol. 2017;37:1241-1249.

30. Anker SD, Doehner W, Rauchhaus M, et al. Uric acid and survival in chronic heart failure: validation and application in metabolic, functional, and hemodynamic staging. Circulation. 2003;107:1991-1997.

31. Kang DH, Park SK, Lee IK, Johnson RJ. Uric acid-induced C-reactive protein expression: implication on cell proliferation and nitric oxide production of human vascular cells. J Am Soc Nephrol. 2005; 16:3553-3562.
32. Choe Y, Kim SK. Association between serum uric acid and inflammation in rheumatoid arthritis: perspective on lowering serum uric acid of leflunomide. Clin Chim Acta. 2015;438:29-34.

33. Kanellis J, Watanabe $\mathrm{S}$, Li JH, et al. Uric acid stimulates monocyte chemoattractant protein-1 production in vascular smooth muscle cells via mitogen-activated protein kinase and cyclooxygenase- 2 . Hypertension. 2003;416:1287-1293.

34. Puddu P, Puddu GM, Cravero E, Vizioli L, Muscari A. Relationships among hyperuricemia, endothelial dysfunction and cardiovascular disease: molecular mechanisms and clinical implications. J Cardiol. 2012;59:235-242.

35. Corry DB, Eslami P, Yamamoto K, Nyby MD, Makino H, Tuck ML. Uric acid stimulates vascular smooth muscle cell proliferation and oxidative stress via the vascular renin angiotensin system. J Hypertens. 2008;26:269-275.

36. Meneshian A, Bulkley GB. The physiology of endothelial xanthine oxidase: from urate catabolism to reperfusion injury to inflammatory signal transduction. Microcirculation. 2002;9:161-175.

37. Vorbach C, Harrison R, Capecchi MR. Xanthine oxidoreductase is central to the evolution and function of the innate immune system. Trends Immunol. 2003;24:512-517.

38. Gersch C, Palii SP, Kim KM, Angerhofer A, Johnson RJ, Henderson GN. Inactivation of nitric oxide by uric acid. Nucleosides Nucleotides Nucleic Acids. 2008;27:967-978.

39. Miesel R, Zuber M. Elevated levels of xanthine oxidase in serum of patients with inflammatory and autoimmune rheumatic diseases. Inflammation. 1993;17:551-561.

40. Andrew C, Bryant RE, Harlan S, et al. Coexistent hyperuricemia and Gout in rheumatoid arthritis: associations with comorbidities, disease activity, and mortality. Arthritis Care Res. 2020;72 (7):950-958.

41. Carlos AA, Robert AT, Marguerite P, Edward P. Does hyperuricemia protect from rheumatoid inflammation? A clinical study. Arthritis Rheum. 1984;27:4

42. Lussier A, De Medicis R. Coexistent Gout and rheumatoid arthritis: “a red marker?” (letter). Arthritis Rheum. 1979;22:939-940.

43. Ames BN, Cathcart R, Schwiers E, Hochstein P. Uric acid provides an antioxidant defense in humans against oxidant and radical-caused aging and cancer: a hypothesis. Proc Natl Acad Sci USA. 1981;78:6858-6862.

44. Elkhouly T, Elnady B, Rageh E. Validity of Doppler subclinical synovitis as an activity marker associated with bone erosions in rheumatoid arthritis patients during clinical remission. Egypt J Radiol Nucl Med. 2016;47(3):985-990.

45. Abdel Sattar M, Alsherbini H. Assessment of synovitis in rheumatoid arthritis by enhanced magnetic resonance imaging (OMERACT RAMRIS score) and power Doppler ultrasound: a comparative study. Kasr Al Ainy Med J. 2017;23(2):96-103.

46. Choi HK, Ford ES. Prevalence of the metabolic syndrome in individuals with hyperuricemia. Am J Med. 2007;120:442-447.

47. Edwards NL. The role of hyperuricemia in vascular disorders. Curr Opin Rheumatol. 2009;21:132-137.

48. George J, Carr E, Davies J, Belch JJ, Struthers A. High-dose allopurinol improves endothelial function by profoundly reducing vascular oxidative stress and not by lowering uric acid. Circulation. 2006;114:2508-2516.

49. McInnes IB, Schett G. The pathogenesis of rheumatoid arthritis. $N$ Engl J Med. 2011;365:2205-2219. 


\section{Publish your work in this journal}

Open Access Rheumatology Research and Reviews is an international, peer-reviewed, open access journal publishing original research, reports, editorials, reviews and commentaries on all aspects of clinical and experimental rheumatology in the clinic and laboratory including the following topics: Pathology, pathophysiology of rheumatological diseases; Investigation, treatment and management

Submit your manuscript here: https://www.dovepress.com/open-access-rheumatology-research-and-reviews-journal of rheumatological diseases; Clinical trials and novel pharmacological approaches for the treatment of rheumatological disorders. The manuscript management system is completely online and includes a very quick and fair peer-review system, which is all easy to use. Visit http://www.dovepress.com/testimonials.php to read real quotes from published authors. 